2016

Community resilience, land degradation and endogenous lock-in effects: evidence from the Alento region, Campania, Italy

Wilson, Geoffrey

http://hdl.handle.net/10026.1/4330

10.1080/09640568.2015.1024306

Journal of Environmental Planning and Management Informa UK Limited

All content in PEARL is protected by copyright law. Author manuscripts are made available in accordance with publisher policies. Please cite only the published version using the details provided on the item record or document. In the absence of an open licence (e.g. Creative Commons), permissions for further reuse of content should be sought from the publisher or author. 


\title{
Community resilience, land degradation and endogenous lock-in effects: evidence from the Alento region, Campania, Italy
}

\author{
Geoff A. Wilson ${ }^{1}$, Giovanni Quaranta ${ }^{2}$, Claire Kelly ${ }^{1}$ and Rosanna Salvia ${ }^{3}$ \\ ${ }^{1}$ School of Geography Earth and Environmental Sciences, University of Plymouth, Drake Circus, Plymouth, PL4 8AA, UK; \\ geoff.wilson@plymouth.ac.uk \\ ${ }^{2}$ UNIBAS, University of Basilicata, DIMIE, Campus di Macchia Romana, 85100, Potenza, Italy; giovanni.quaranta@unibas.it \\ ${ }^{3}$ MEDES, Foundation for Sustainable Development of the Mediterranean, C/da San Licandro 1, 84029, Sicignano degli Alburni, SA, Italy; \\ rosanna@medes.eu
}

This is an Accepted Manuscript of an article published by Taylor and Francis in Journal of Environmental Planning and Management 2015, available online: http://dx.doi.org/10.1080/09640568.2015.1024306 and in Volume 59(3), pages 518-537

\begin{abstract}
This study analyses social, economic and political 'lock-ins' for understanding community resilience and land degradation. The study focuses on lock-ins from within communities, using four case study communities in Italy affected by land degradation. The analysis highlights the complex interrelationships between various lock-ins, and suggests that the communities are on pathways of declining resilience that may lead to increasing difficulties in addressing land degradation issues in future.
\end{abstract}

\section{Introduction}

Ever since Adger's (2000) seminal article on the importance of understanding resilience at community level, the notion of 'community resilience' has assumed increasing importance (Cote and Nightingale, 2012). As a result, a plethora of studies have been conducted that address resilience from a variety of perspectives such as community resilience and natural disasters, climate change or rural/urban resilience (e.g. Masten and Obradovic, 2008; Forbes et al., 2009; Wilson, 2012b). Yet, although resilience is generally seen as "the capacity of a system to absorb disturbance and reorganize while undergoing change to still retain essentially the same function, structure, identity, and feedbacks" (e.g. Forbes et al., 2009: 22041), there continues to be substantial disagreement about what community resilience means and what the key processes are that should be addressed to make communities more resilient (Adger, 2000; Wilson, 2012a). Most authors agree that resilience should be assessed with regard to natural or human-made shocks and disturbances that affect communities (Davidson, 2010), and that community resilience can only be understood if it is assessed against specific disturbances such as climate change, or economic or social upheaval. Resilience research is, thus, important as it helps in assessing how and why disturbances affect the ability of communities to thrive, or in some cases, survive (Wilson, 2012a).

While the response of communities to 'disasters' or 'hazards' feature strongly in resilience studies, less work appears to have been undertaken at the interface between community resilience and land degradation, in particular how the resilience of communities facing desertification, loss of productive capacity of soils, and landslides has been affected. Apart from studies that indirectly link vulnerability with land use management (e.g. Wilson, 2013), few studies have explicitly linked questions about community resilience with land degradation processes. Exceptions can be found in recent issues of the journal 'Ecology and Society', which have highlighted the importance of understanding how land degradation affects community resilience, in particular in special feature articles addressing issues of 
resilience and vulnerability in arid and semi-arid social ecological systems (e.g. Sendzimir et al., 2011), dryland pastoral systems, or Mediterranean drylands (e.g. Lopez-Gunn, 2012, for Spain). Fraser et al. (2011), for example, highlighted that over $40 \%$ of the earth's land surface are drylands and home to approximately 2.5 billion people whose resilience is often threatened by complex interlinked social, economic and environmental changes. They particularly argued that "research is needed to explore how development strategies and other socio-economic changes help livelihoods become more resilient and robust at a time of growing ... risk and uncertainty" (Fraser et al., 2011, 1). Sendzimir et al. (2011) similarly investigated processes needed to rebuild resilience in desertification-prone areas of the Sahel region, highlighting the complexity of actor interactions in resilience processes in communities affected by land degradation, while Walker et al. (2009) focused on understanding resilience, adaptability and transformability in a severely eroded region of south-east Australia. Crane (2010), on the other hand, focused on understanding 'cultural resilience' processes in social-ecological systems, and emphasised that land degradation is often culturally constructed, resulting in highly variable adaptive pathways. These and other studies have highlighted that land degradation processes severely affect the survival of human communities.

Social, economic and environmental 'lock-ins' have been shown to be particularly important for understanding challenges and opportunities for raising community resilience. Lock-in effects can be understood as drivers that shoehorn certain community decisionmaking processes into specific 'pathways' or development 'corridors' beyond which certain human decision-making actions become either 'unthinkable' or impossible to implement (Wilson, 2012a, 2013). In this study we are particularly interested in lock-in effects that emanate from within the community itself - endogenous lock-ins -whilst acknowledging that community-level decision making pathways can never be fully divorced from wider pressures and drivers at regional, national and international levels.

Three intertwined endogenous lock-in effects that influence pathways of change at community level have been identified in the literature. First, structural lock-in effects are pathway-related lock-ins linked to processes usually beyond the control of individual communities and, therefore, permeate the boundaries between the local community and wider society. These include structural factors that shape societies such as societal moral codes, traditions, religion and rites; the political orientation of a region/community; and other moral and behavioural codes associated with, for example, gender relations or property rights (Wilson, 2013). Structural-physical factors such as the embeddedness of communities within transport, food and energy networks, or the geographical location of a community with constraints and opportunities for economic development/tourism, are also important. Moral codes particularly define the philosophical basis upon which community action takes place, and find expression through traditions and specific rites that are usually influenced by factors beyond community level (Davidson, 2010). Typical examples relate to the inherent conservatism of rural communities or adherence to notions of a 'rural idyll' aimed at preserving the 'charm' of the countryside and to 'keep things as they are' (Wilson, 2012b).

Second, economic lock-in effects are directly associated with economic capital and are particularly associated with path dependencies related to poverty at community level as a key component of vulnerable communities (Rigg, 2006; Chaskin, 2008). The lack of financial resources means that these communities have little opportunity to address land degradation issues, either in the form of improved environmental management strategies or through inability to devote sufficient time and energy beyond immediate survival needs. On the other hand, access to markets for community-based products can substantially increase the wealth of communities, although it is important to note that endogenous economic lock-in effects are complex, and profit-driven lock-ins can become evident as certain stakeholder groups 
increase their dependence on market forces and find it increasingly difficult to 'break out' from profit maximization pathways. This is often exacerbated by shifts in patterns of community-level production from local/regional to national/global, and lock-in effects associated with the loss of alternative economic pathways for local stakeholder groups (Wilson, 2012b).

One of the most interesting set of lock-ins are socio-psychological lock-in effects associated with community-level endogenous social and psychological factors. The literature suggests that many stakeholder groups within communities are often reluctant to break path dependencies and change towards more resilient trajectories because of entrenched psychological conservatism, often also referred to as 'cultural resistance' (Burton et al., 2008). Although adopting new technologies to 'fix' community problems may be relatively easy, developing a new attitude and shifting culture from one mental mode to another is difficult (Wilson, 2013). Traditional farming communities - which will feature prominently in our empirical analysis below - are a particularly appropriate example of psychological conservatism due to their strong embeddedness with farming lifestyles, local landscapes and community networks, meaning they are often resistant to change (Burton et al., 2008). Although such conservatism can be positive in terms of environmental management at community level (e.g. by adhering to 'traditional' farming practices that may alleviate land degradation processes), it can also stifle innovation and change regarding the strengthening of social and natural capital. Both Cutter et al. (2008) and Wilson (2013) suggest, therefore, that vicious cycles of psychological conservatism may be in operation precisely when communities affected by land degradation may be in most need of innovation and openmindedness. Subtle psychological forces are also at play here, especially as poor timing, excessive pressure for change or misguided lobbying, may tip the balance away from decisions for 'positive' change, highlighting the crucial roles of power and community leadership (Scheffer et al., 2003).

The notion of social memory at community level is particularly important for the direction of endogenous 'locked-in' pathways, and any community will carry with it the memory ('baggage') of previous decision-making pathways (Wilson, 2012a). Learning pathways are particularly important to understand endogenous path dependency and lock-in effects, and that these pathways are usually characterised by complex stakeholder interactions based on intricate power structures within communities (Davidson, 2010). This means that there are usually multiple stakeholder pathways within communities, with multiple and often overlapping path dependencies and lock-ins. In addition, due to the close association with conservatism, lethargy and a lack of willingness for change noted above, endogenous lock-in effects are often associated with negative community development processes which lead to loss of resilience (Scheffer et al., 2003). Endogenous lock-in effects, thus, often result in negative processes that, as the term implies, lock stakeholder groups or entire communities into pathways from which it may not be easy to 'escape'.

Building on these studies, and echoing Moser's (2010) and Cote and Nightingale's (2012) recent calls for more socially relevant research on resilience, the aim of this study is to investigate the importance and implications of lock-in effects at community level and how they impact on resilience processes in communities affected by land degradation. A specific objective will be to assess lock-ins associated with structural, economic and sociopsychological variables such as poverty, access to markets, infrastructural lock-ins, skills transfer, bonding and bridging capital, social memory and traditions, and how these affect resilience in four case study communities affected by land degradation in the Campania region of Italy. 


\section{Methodological considerations}

\subsection{Selection of case study communities}

Case study communities ${ }^{1}$ in the Alento region of south-western Campania (southern Italy) were selected for this study as part of the large-scale LEDDRA international study on responses to land degradation (LEDRRA, 2013) (Figure 1). All LEDDRA case studies were selected on the basis of being threatened by natural and anthropogenic land degradation processes that fall under the United Nations Convention for Combating Desertification definition of 'severe loss of productive capacity of soils'. Key land degradation issues in the chosen communities included degradation of terraces, loss of productive capacity of soils, degradation of vegetation, and landslides (Piccaretta et al., 2006; UNCCD, 2011) - processes which increasingly threaten the survival of these communities.

\footnotetext{
${ }^{1}$ Although definitions of 'community' vary considerably (Wilson, 2012a), in our study communities were villages with a clearly defined community boundary (administrative), clearly attributable land ownership patterns (i.e. most farmers belonging to one specific community), and with evident cultural attachment of residents to 'their' specific community.
} 


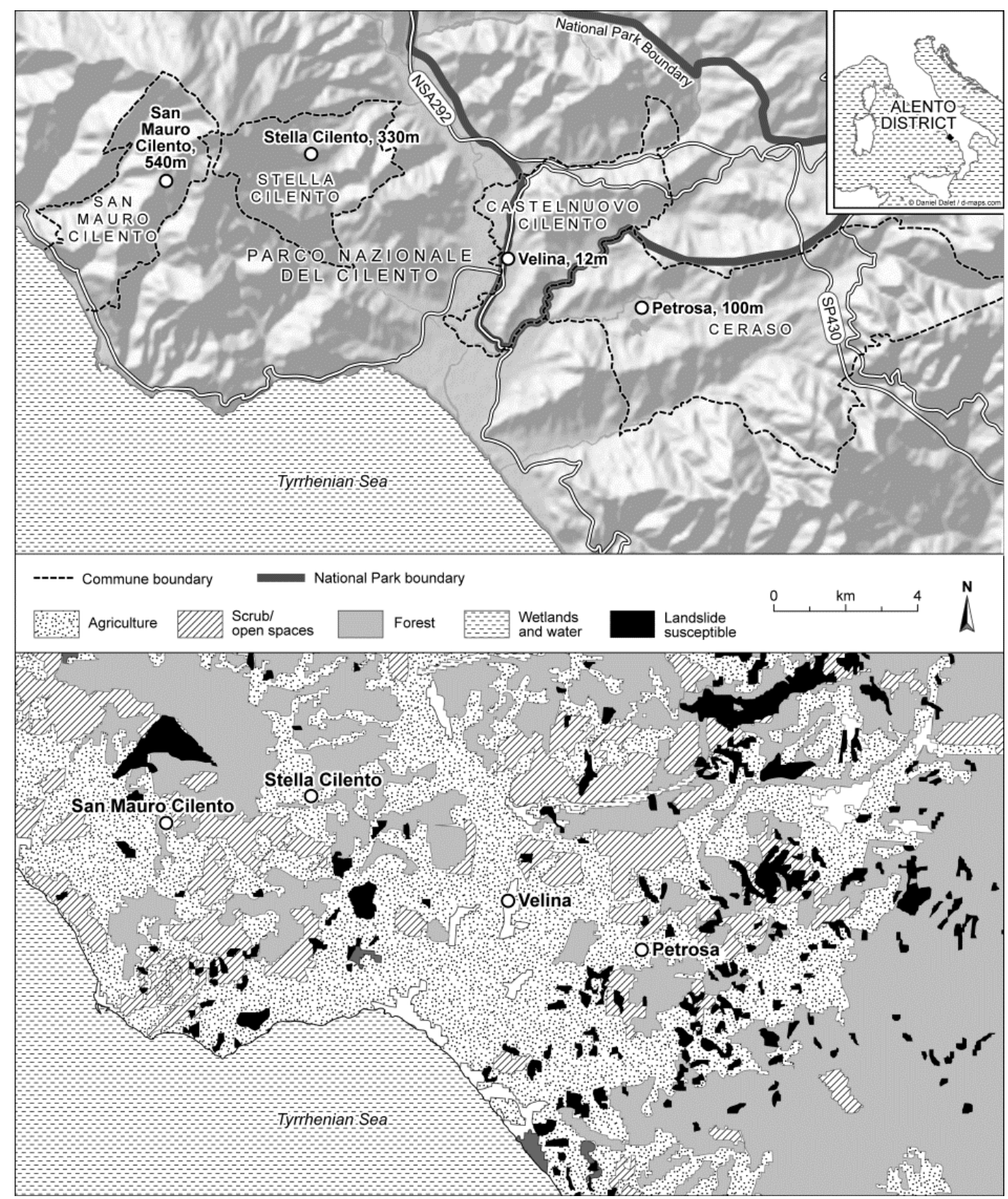

Figure 1: The Alento district with the four case study communities, main land use types, and landslide susceptible areas (Source: authors; after CORINE Land Use Classification, 2006)

The methodology for selection of the communities ensured that a wide range of different types of communities/stakeholder groups were included to assess structural, economic and socio-psychological lock-in effects on community resilience. The selection included two communities in the more fertile lowlands (Velina, Petrosa) and two relatively remote communities in mountain areas near Monte Cilento (Stella Cilento, San Mauro Cilento), with all four communities within about $10 \mathrm{~km}$ of each other. Stella Cilento and San Mauro Cilento are located within the boundaries of the Cilento and Vallo di Diano National Park (established 1991). All four Alento communities suffer from land degradation related to both human and natural drivers of change (Piccaretta et al., 2006; Xiloyannis et al., 2008), including the dismantling of terraces due to land abandonment, often exposing soils to erosion. Farmers in all four communities also received CAP production subsidies between the 1970 s and early 2000s, which propelled farmers towards productivist agricultural intensification (see below). Agricultural land covers about $60 \%$ of the four case study 
communities (see Figure 1), with olive groves, pastures and chestnut groves prevalent in mountainous areas, and permanent crops, fruit orchards, maize and vineyards in the lowlands, while planted or natural forests (beech and oak) cover the remainder. Average farm size is only 2.4 ha, highlighting that generating sufficient income from farming is difficult, with many part-time farmers and high levels of pluriactivity. The Alento region is also characterised by pronounced land fragmentation, and although agricultural production has been boosted through the establishment of local cooperatives and associations, fragmentation has reduced agricultural profitability and complicated efforts to carry out the streamlining needed to ensure that this sector can continue to compete internationally.

In recent decades, all four communities have seen substantial depopulation, including outmigration of young people, leading to land abandonment and the loss of labour needed to maintain traditional agricultural management techniques. Abandonment of terraces in marginal agricultural locations has been a particularly negative result of outmigration processes and has led to soil loss in steep terrain, although in some areas semi-natural vegetation has re-grown protecting vulnerable soils. Outmigration has had severe repercussions for social and economic capital in these communities, although the Alento continues to be well known for its high quality local products (e.g. olive products, mozzarella, specialist cheeses, local meat products). As Piccaretta et al. (2006) have highlighted, these anthropogenic processes have been exacerbated by natural processes linked to climate change, especially through worsening summer droughts interspersed by extreme rainfall events that have led to increased soil erosion. Another driver of erosion is forest fires and, as many of the abandoned olive groves border on forests, fires originating in these areas can spread fast and exacerbate already existing erosion problems.

Table 1 shows specific characteristics for the 4 selected communities and highlights the higher dependency of the two upland communities (Stella Cilento, San Mauro Cilento) on agricultural incomes. The service sector is better developed in the lowland communities of Velina and Petrosa, although agriculture still plays an important role. GDP per capita is highest (€14,500/capita) in San Mauro Cilento (partly due to a well developed agricultural cooperative; see below) and lowest in Petrosa (€9900/capita) but is low overall for all four communities compared with the $€ 30,500 /$ capita (in 2011) Italian GDP.

\begin{tabular}{lllll} 
& Stella Cilento & San Mauro & Velina & Petrosa \\
Population & 880 & 980 & 860 & 100 \\
Altitude (m) & 386 & 560 & 12 & 87 \\
GDP per capita (€) & 11,000 & 14,500 & 13,800 & 9900 \\
Main economic & Agriculture 1.3 & Agriculture 1.8 & Agriculture 1.6 & Agriculture 2.6 \\
\multicolumn{1}{c}{ sectors (yearly } & Industry/constr 1.7 & Industry/constr 2.1 & Industry/constr 9.3 & Industry/constr 5.0 \\
turnover m€) & Services 7.4 & Services 12.7 & Services 30.9 & Services 22.1
\end{tabular}


Table 1: Economic and population characteristics of the four Alento case study communities (Source: authors)

\subsection{Methodologies for assessing community resilience}

The study followed established methodologies to assess community resilience (e.g. Cumming et al., 2005; Resilience Alliance, 2007; Wilson, 2012a), and included several methodological steps that enabled cross-checking and iterative validation of data. The assessment of community resilience and endogenous lock-ins was based on qualitative methodologies comprising interviews (both structured and in-depth), roundtable discussions, workshops and observation, complemented with quantitative information from secondary sources focusing mainly on economic data. A local Italian team based at the University of Basilicata collected data based on their detailed knowledge of the communities and the specific land degradation challenges that each faced. Resilience was assessed based on a well-established set of key variables identified in the resilience literature and included both economic/structural components as well as social/political components, acknowledging that clear boundaries do not necessarily exist between these and that all lock-ins are closely interlinked with each other (see in particular Cumming et al., 2005; Wilson 2012a, 2013).

Table 2 shows key individual variables associated with lock-ins identified in the resilience literature which are believed to raise or lower community resilience (see in particular Cumming et al. [2005], and the Resilience Alliance [2007] workbook for practitioners). Structured interviews were held with local stakeholders and drew on a list of ca 200 questions (both proxy indicators and indicators directly linked to lock-in variables shown in Table 2). In addition to structured interviews, in-depth interviews were held with key community representatives (ca 5-10 interviews per community) to understand how degradation is addressed at community level and by whom, and to identify complex issues of community cohesiveness, corruption, or community-based learning processes (bonding and bridging capital). Observational methodologies were used to better understand stakeholder interactions and to assess the effectiveness of measures to alleviate land degradation, supplemented by roundtable discussions and two workshops with key community representatives (e.g. mayors, planners, farmers). Specific emphasis was placed on the representativeness of the individuals/stakeholder groups interviewed, and on issues related to power networks. Overall, the data collection process took two years (2010-2012), which enabled an iterative process of in-depth communication and feedback with respondents about specific questions.

\begin{tabular}{|c|c|c|}
\hline Examples of lock-in variables & As an attribute raising resilience & $\begin{array}{l}\text { As an attribute lowering } \\
\text { resilience }\end{array}$ \\
\hline Poverty & Alleviation of poverty & Worsening poverty \\
\hline Access to funding & $\begin{array}{l}\text { Good access can raise resilience (but may } \\
\text { also create funding dependence) }\end{array}$ & Limited access tends to lower resilience \\
\hline $\begin{array}{lll}\text { Markets for } & \text { community-based } \\
\text { agricultural products }\end{array}$ & $\begin{array}{l}\text { Good access to markets raises resilience by } \\
\text { raising income }\end{array}$ & $\begin{array}{l}\text { Poor access or poorly developed markets } \\
\text { lowers resilience }\end{array}$ \\
\hline Infrastructural lock-ins & $\begin{array}{l}\text { Improved roads and connections raise } \\
\text { resilience }\end{array}$ & Poor infrastructure lowers resilience \\
\hline Post-2008 economic recession & $\begin{array}{l}\text { Has forced young people to return to } \\
\text { communities thereby potentially raising } \\
\text { resilience }\end{array}$ & $\begin{array}{l}\text { Has lowered resilience by reducing tourism } \\
\text { and income for communities }\end{array}$ \\
\hline Land abandonment & Re-use of abandoned land raises resilience & Worsening land abandonment lowers \\
\hline
\end{tabular}




\begin{tabular}{|c|c|c|}
\hline & & resilience \\
\hline $\begin{array}{l}\text { Land management } \text { skills passed on } \\
\text { through generations }\end{array}$ & $\begin{array}{l}\text { Raises resilience if appropriate skills are } \\
\text { passed on effectively }\end{array}$ & Lowers resilience if skills are lost \\
\hline Outmigration of young people & $\begin{array}{l}\text { Reversing outmigration raises community } \\
\text { resilience }\end{array}$ & Worsening outmigration lowers resilience \\
\hline Bonding capital: trust & Raises resilience if well developed & Lowers resilience if poorly developed \\
\hline Bonding capital: corruption & $\begin{array}{l}\text { Exposing and fighting corruption raises } \\
\text { resilience }\end{array}$ & Corruption usually lowers resilience \\
\hline $\begin{array}{l}\text { Bonding capital: } \\
\text { structures/governance }\end{array}$ & $\begin{array}{l}\text { Raises resilience if community governance } \\
\text { is transparent and inclusive }\end{array}$ & $\begin{array}{l}\text { Lowers resilience if governance is poorly } \\
\text { developed and exclusive }\end{array}$ \\
\hline $\begin{array}{l}\text { Bridging capital: stakeholder interactions } \\
\text { across communities }\end{array}$ & Raises resilience if well developed & Lowers resilience if poorly developed \\
\hline $\begin{array}{l}\text { Bridging capital: interactions with policy- } \\
\text { makers }\end{array}$ & Raises resilience if well developed & Lowers resilience if poorly developed \\
\hline Social memory and traditions & $\begin{array}{l}\text { Can raise resilience if linked to knowledge } \\
\text { of sustainable land management }\end{array}$ & $\begin{array}{l}\text { Lowers resilience if sustainable land } \\
\text { management knowledge is lost }\end{array}$ \\
\hline $\begin{array}{ll}\text { Psychological } & \text { conservatism/cultural } \\
\text { resistance/inertia } & \\
\end{array}$ & $\begin{array}{l}\text { Can act as a brake on inappropriate } \\
\text { development or change }\end{array}$ & $\begin{array}{l}\text { Lowers resilience if acts as a brake on } \\
\text { appropriate innovation }\end{array}$ \\
\hline
\end{tabular}

Table 2: variables associated with lock-ins and how they raise or lower community resilience

(Source: authors; after Cumming et al., 2005; Wilson, 2012a, 2013)

All lock-in variables analysed were 'non-directional variables' (Cumming et al., 2005) that can either raise or lower resilience, depending on each specific community context. Analysis of whether a variable contributed towards raising or lowering community resilience was based on an iterative process that attempted to draw out key themes that highlighted links between the lock-in and resilience issues. Drawing on analysis of all the various strands of data, an assessment of resilience was produced for each community based on a 5-point scale from very high to very low resilience.

\section{Lock-in effects and land degradation in Alento communities}

Based on the key qualitative variables (Table 2) identified as contributing towards raising or lowering community resilience, Figure 2 provides a graphic depiction of the complex interrelationships between individual lock-ins, their contribution to raising or lowering resilience and the resultant ability to address land degradation issues in the four communities (shown as very low/low/moderate/high/very high resilience). In all cases, linkages operate in both directions, i.e. no lock-in occurs in isolation, and 'ripple effects', which raise or lower community resilience, can be set in motion by subtle changes within just one of the variables (e.g. outmigration of young people leads to further land abandonment which, in turn, leads to worsening land degradation). The following discussion will analyse individual lock-in variables and how they have affected the resilience of the study communities to address land degradation issues. 


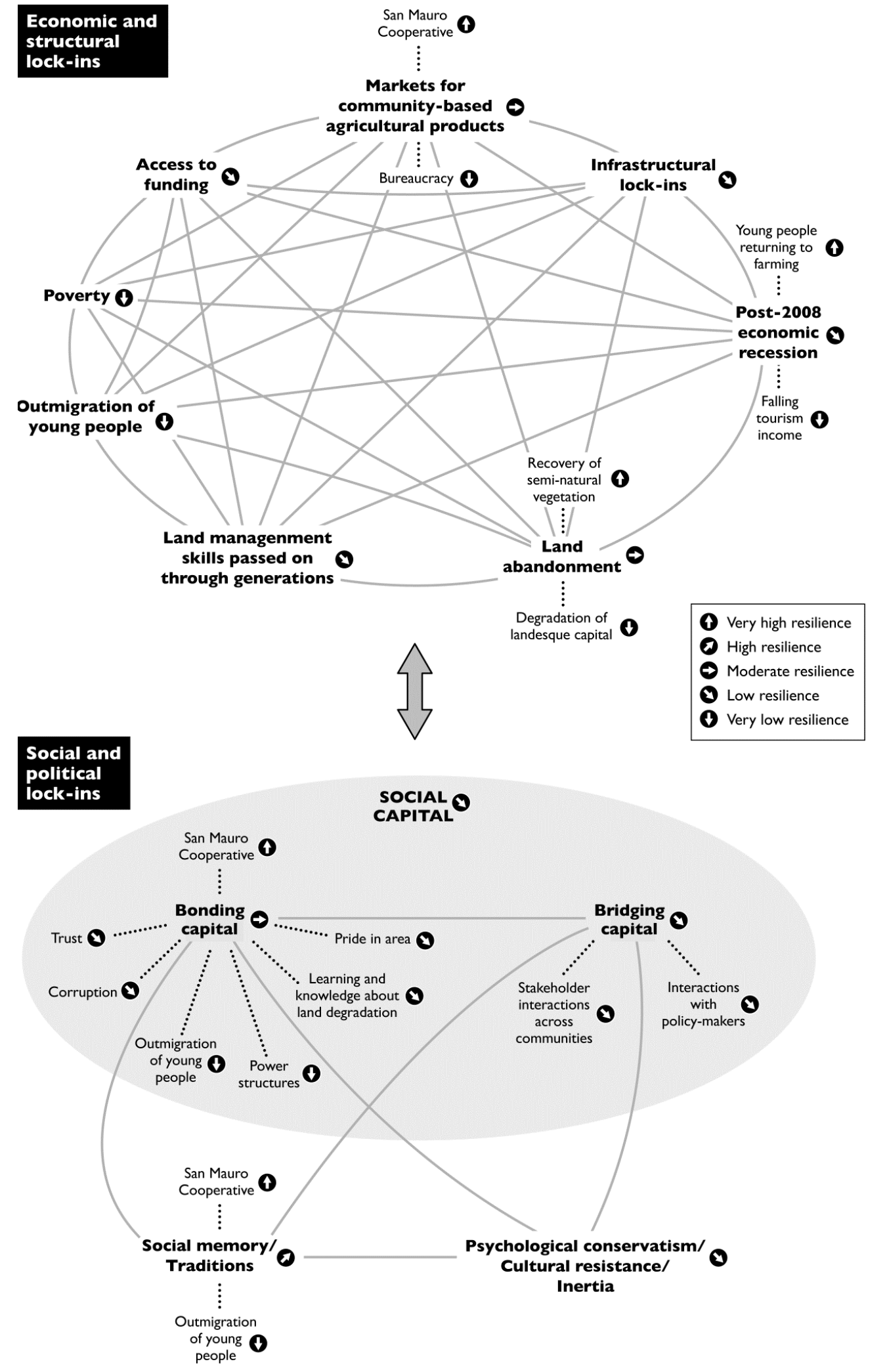

Figure 2: Economic, structural and socio-political lock-ins, resilience, and lock-in interactions in the four Alento communities (Source: authors)

\subsection{Economic and structural lock-ins}


Figure 2 (above) shows that economic lock-ins are important for understanding constraints faced by the study communities to successfully address land degradation issues. One of the most important lock-ins is associated with relative poverty and the lack of readily available finances to deal with land degradation. Table 1 (above) already highlighted that GDP per capita is low in all four communities compared to the Italian average. Poverty particularly affects the ability of stakeholders to address land degradation, as all four communities are still reliant on agricultural incomes (e.g. Stella Cilento 14\%; San Mauro Cilento 11\%). The reasons for poverty lock-ins in the four communities are complex and closely associated with structural and socio-economic constraints that characterise economic development in southern Italy (Pomarici and Vecchio, 2013), but factors such as land fragmentation, small farms (average only $2.4 \mathrm{ha}$ ) and few opportunities for work are among the most important constraints. As Figure 2 shows, poverty emerges as a key lock-in contributing to 'very low' resilience.

Relative poverty also occurs because many farmers have found it difficult to access financial resources, including subsidies and business development finance. Many stakeholders mentioned that although agricultural subsidies over the past decades have helped many farmers survive, small farms often have problems accessing funding while others "have opted out as they are too daunted by the bureaucracy surrounding the process" $(\mathrm{P} 6)^{2}$. Interviews suggested that smaller farmers often lacked confidence, experience and/or capacity to tackle complex forms and cope with the application process, especially when it came to subsidies for farm diversification or on-farm processing. Respondents also felt that there was a lack of information about what subsidies are available, and lack of support for individuals in accessing available funding (see also Pomarici and Vecchio, 2013). However, while most interviewed farmers agreed that agricultural subsidies played a relatively important part in farm survival for some, access to funds from external sources was not available as eligibility is largely based on asset availability and specific socio-economic characteristics of each farm. In addition, all four communities struggled to access nonagricultural funding because of a lack of information and/or leadership within the communities, and many respondents appeared to have only limited information about EU funding that could be relevant for their area (e.g. LEADER projects for tourism development). There was a general perception, therefore, that in the past, the economy appeared to be more stable, with farm incomes sufficient to support farming families. This echoes results from other Mediterranean areas where farm incomes have declined to such an extent that survival of families from farming alone is rarely sufficient (e.g. Oliva, 2010, for Spain). Nonetheless, some felt that there were opportunities and resources for economic development available which had not yet been tapped, especially with regard to specialist foods (see below) and tourism. Overall, funding-related lock-ins contributed to 'low' resilience in all four communities.

Given the limited financial resources available, access to existing markets for communitybased agricultural products, particularly olive oil, has been key for the four case study communities. Yet, access to markets varies substantially. While respondents in Velina and Petrosa (lowlands) had fewer problems due to better infrastructure connections and nearby coastal tourist areas, the upland communities of Stella Cilento and San Mauro Cilento have struggled to place their products. The most innovative (and arguably most resilient) initiative - the Nuovo Cilento Cooperative in San Mauro Cilento (see Figure 2) - was set up to promote the production and sale of high quality olive oil and has also had beneficial impacts

\footnotetext{
${ }^{2}$ Individual quotes are anonymised and respondents are labelled according to which communities they come from (Stella Cilento [SC], San Mauro Cilento [SM], Velina [V] and Petrosa [P]).
} 
with regard to alleviation of land degradation. This cooperative has 190 members who farm ca 1300 ha of agricultural land in and around San Mauro Cilento, and is the largest producer of organic and PDO-certified olive oil in Italy. Almost all San Mauro Cilento farmers are members of the Cooperative, which uses traditional local olive cultivars, does not use fertilisers or pesticides, and hand picks fruits which are then cold-pressed to retain more nutrients. Interview respondents suggested that this has reduced the threat of land degradation, especially as remnant agricultural waste is spread to protect soils from desiccation and erosion. Most importantly, the cooperative is also involved in campaigns for greater environmental and consumer awareness in the area, disseminates information about repair and maintenance of terraces, and encourages other farmers to use and (re)value ancient types of olive trees which are better suited to local soil protection needs. In addition, the cooperative also helps with information and communication about CAP subsidies and erosion management practices. Profit generated by the cooperative goes back to its members, over 50 jobs have been created, and the cooperative also manages a well-known restaurant that serves traditional dishes using locally produced olive oil. A local farmer suggested that "the cooperative is a sort of saving grace for farmers who otherwise would have no means of learning new skills or selling many of their products" (SM5). Due to its success, the cooperative has helped prevent further land abandonment and many respondents argued that it has acted as an example of 'best practice' for the whole region and is one of the key reasons why per capita GDP is higher in San Mauro Cilento (see Table 1 above). As Figure 2 suggests, therefore, the San Mauro Cilento Cooperative has substantially contributed to raising the resilience of that community.

Interestingly, the San Mauro Cilento cooperative has been the only successful cooperative, as the other three communities have tried and failed to establish equally successful ventures. As a result, most respondents from these communities argued that developing and marketing local products remains difficult (i.e. only 'moderate' resilience overall; see Figure 2). One respondent from Petrosa, for example, argued that "economic development will be difficult without some sort of intervention to re-launch local produce onto the market" (P1). Although some respondents highlighted some success at direct marketing olive oil products to local tourists (P11, P12), most lamented the lack of an 'entrepreneurial mindset', excessive bureaucracy to set up new businesses, tough regulations for the sale of dairy products, low prices, and a limited appetite to innovate or add value to local products.

The lack of alternative economic opportunities is further exacerbated by infrastructure lock-ins, in particular poor road networks and quality, which prevents tourist coaches from accessing the area. One Stella Cilento respondent argued that "there are no prospects for future economic development. Just looking at the roads, you can see the level of neglect. In the summer months when tourists arrive the roads are practically impassable. There are often landslides or fallen vegetation" (SC6). Figure 2, therefore, suggests that infrastructure lockins have contributed to 'low' resilience in the case study communities.

A key problem closely associated with these economic lock-ins is outmigration of young people, which emerges as a key factor lowering community resilience (see Figure 2) by preventing knowledge and skills in sustainable soil management being passed on to the next generation,. A mood of pessimism was evident in all four communities, and many argued that "emigration has always been a problem in the area, young people nearly all migrate away" (V10). Young people have little direct engagement with community matters and projects and do not partake in decision-making affecting the community. As one Velina respondent argued, "the same old people always make the decisions for the area" (V2), while a Petrosa resident further argued that "there are very few young people left and those who have remained are reluctant to participate in community initiatives or decision-making processes" (P12). These processes are exacerbated by the lack of secondary schools in any of the four communities 
that could, in theory, refocus attention on local land use and land degradation issues in the area.

In addition, and echoing other studies (e.g. Fairhead and Scoones, 2005), in all four communities local knowledge and skills regarding key land management issues are only moderately passed on from the older to the younger generation, with many interviewees suggesting that there was more intergenerational dialogue in the past. Similarly, the older generation appears to be only moderately interested in passing their knowledge about land degradation to young people (e.g. expertise in building dry stone walls), and many interviewees felt that young people's aspirations were no longer rooted in skilled local work but were centred on university and office jobs. Worst of all - and closely interlinked with above-mentioned economic lock-ins - is the lack of local job opportunities for young people and their general reluctance to take over family farms. This was echoed by a young Stella Cilento respondent who suggested that "local knowledge is still useful in addressing land degradation problems, but unfortunately we are losing that knowledge. My grandfather knew a lot more about environmental resources than I do" (SC3). As both Fairhead and Scoones (2005) and Stump (2010) suggested, this inevitably lowers resilience as it reduces the ability of communities to address land degradation issues (see Figure 2).

These economic lock-ins are closely intertwined with land abandonment, which is an increasingly important problem in all communities but especially in the mountain communities of Stella Cilento and San Mauro Cilento. A craftsman from Velina argued that "a big problem is that the land is no longer farmed like before and nothing is produced". The abandonment of agricultural activities represents a core problem not only for land degradation (e.g. degradation of landesque capital such as terraces), but is also a potential risk for other economic activities in the community, such as the agri-tourism sector which is dependent on environmental quality and local agricultural products. Yet, in all four communities land abandonment has also had 'positive' outcomes, not only with regard to some degraded land being recolonised by semi-natural vegetation and forest, but also through increased availability of land for local needs. Shortage of land - a key issue in the past - is, therefore, no longer a problem. Similarly, partly due to outmigration, property rights are no longer an issue and respondents were unanimous in arguing that most community members have equal access to land and its natural resources, despite the fact that some large landowners with power and economic influence persist in the area. Thus, as Figure 2 shows, while degradation of landesque capital has substantially reduced resilience (especially through terrace collapse and increased risk of landslides), the regrowth of vegetation on some abandoned land has substantially reduced the threat of land degradation (by better anchoring the soil), suggesting that land abandonment overall emerges as a 'neutral' variable with regard to raising or lowering resilience.

Inevitably these economic lock-ins have been influenced by the post-2008 economic recession, with both positive and negative impacts. For example, all four communities have been negatively affected with regard to fledgling tourism development initiatives (substantially lowering resilience). Nonetheless, the post-2008 economic crisis has also meant that (some) young people have come back into the villages and are more willing than in the recent past to take over family farms (potentially raising resilience by farming former abandoned land) (see Figure 2).

Taken together, the evidence from the communities suggests that economic lock-ins provide a powerful explanation of why the four case studies have lost resilience and are struggling to find new pathways to address land degradation. Despite the successful San Mauro Cilento olive oil cooperative and some goodwill by key policy stakeholders mentioned during stakeholder workshops, the communities are locked into economic pathways that do not provide many opportunities for the development of innovative and forward-looking 
initiatives that would help revalue often derelict or underused agricultural land. Land degradation issues in the area are, thus, partly a result of lack of opportunities for community members to develop more vibrant alternative local economies.

\subsection{Socio-political lock-ins}

Socio-political lock-ins are among the most complex and interesting lock-ins affecting interlinkages between community resilience and land degradation. Figure 2 (above) shows that socio-political lock-ins in the four communities are closely interlinked with economic lock-ins, especially through the link between poverty/outmigration/lack of alternative economies and social capital at community level, traditions and social memory, power and conflict, psychological conservatism, and the gradual disintegration of human-environment interactions. As both Adger (2000) and Wilson (2012a) emphasised, lock-ins associated with social capital are particularly important in this respect, and our results suggest that while there are still some remnants of bonding capital ('vertical' stakeholder interactions within communities) in these 'traditional' tight-knit southern Italian communities, bridging capital (horizontal stakeholder interaction between communities and the region) has declined.

With regard to bonding capital (Figure 2), respondents suggested that stakeholder trust is poorly developed across all four communities, with comments made that neighbours no longer trust each other, that general neighbourhood support is often weak, and that there is a frequent "absence of common interest" (V8). One Velina resident suggested that "neighbours don't really trust each other, there is a culture of individualism, everyone looks after their own interests first" (V1), with severe repercussions for the ability of the community to communally address land degradation issues. Many suggested that trust has been gradually lost over time, that there are few strongly linked stakeholder networks or community groups, and that lack of community engagement and lack of 'connectedness' between individuals is one of the biggest problems. Echoing Buikstra et al. (2010), this situation is exacerbated by negative lock-ins associated with lack of trust between community residents and powerful individuals/community leaders. In Stella Cilento, for example, most respondents argued that community leaders do not facilitate interaction and that "decisions are always made by the same group of individuals, everyone else is excluded" (SC8). Similarly, many lamented that key decisions are taken by only a few (e.g. V3) and that farmers and young people are particularly excluded from local decision-making (V2, V8). Others felt that those in power wanted to keep the status quo, and so making change happen was difficult. This suggests that community governance structures are not currently able to cope with problems due to lack of dialogue and trust with those in power, making the communities only moderately self-reliant in dealing with problems. Overall, therefore, lack of trust across several stakeholder groups has tended to lower community resilience (see Figure 2).

This finding suggests that power structures act as a constraint rather than an opportunity for raising community resilience and solving land degradation problems, with respondents mentioning that certain groups (e.g. women; young people; less powerful members of the community) are often excluded. This suggests that decision-making structures with regard to land degradation are not fully inclusive, at times hinder participation, and that some key decisions are made behind closed doors. Even more worrying is the fact that most respondents agreed that there are 'negative' informal power structures (e.g. certain families with relatively large power), although a few argued that these power inequalities were worse in the past. As a result, most respondents were dissatisfied with how decision-making power is assigned, and most community members did not feel empowered to act, with apathy and 
distrust between those in power and residents over how to best tackle land degradation as key issues.

These lock-ins are also reflected in the fact that there appears to be little real pride in the area. Comments such as "there is no longer a sense of pride or belonging in the community, as such our community is very much losing its original identity" (SC1) were common. Echoing the above discussion with regard to frustrations felt by young people, most respondents suggested that older people were 'happier', while young people were increasingly frustrated about the lack of opportunities with frequent reference to feelings of 'resignation' with regard to the future. 'Lack of pride in the area', thus, emerges as another key lock-in that has tended to reduce community resilience.

Corruption among those who hold power in the communities is an additional problem, further undermining stakeholder trust and affecting the quality of bonding capital. Petrosa respondents, for example, commented on the weakness of local leaders in dealing effectively with abuse of economic resources, while one farmer argued that "yes, there is corruption, and it is such a difficult problem to eradicate as it is so deeply rooted in the culture of the community" (SM7). Respondents were sceptical about whether community leaders facilitated interaction and collaboration between groups because of corruption. In addition, inclusion of individuals or groups in communication processes appears to be only weakly developed, and, in particular, communication among stakeholders is weak - the latter suggestive of communities that may communicate at times of extreme crises, but that, on the whole, suffer from lack of communication on day-to-day land degradation issues.

In addition, data on communication between stakeholder groups suggests that learning and knowledge about land degradation issues is only moderately well developed. Weaknesses in passing local knowledge and skills from the older to younger generations were clearly apparent. Indeed, several interviewees highlighted a fracture between older and younger generations and a concurrent lack of knowledge transfer. One farmer argued that "there is a generational gap and young people and older generations rarely have the opportunity to spend time together" (SM2), while another suggested that "there is no knowledge transfer, which means people need to bring in experts from outside the community" (SM8) (see also Buzzanell, 2010). Yet, despite mixed responses, the land degradation knowledge held by older generations still appears to be valued, supported by the fact that older people contribute their knowledge to help with responses to land degradation. The most worrying aspect of learning and knowledge processes, however, is that there is only limited evidence that knowledge and skills are actually passed on from younger to older generations. This suggests that either young people are no longer strongly involved in land degradation-related learning and knowledge processes and, therefore, do not have 'much to say' about land degradation (see above), or that the older generation values learning and knowledge of young people less in a village community increasingly characterized by growing knowledge rifts between old and young. This is directly linked with the moderately developed processes associated with knowledge utility and transfer, suggesting that transferring key information about optimum responses to land degradation is difficult within and across the four communities. However, other components of knowledge utility and transfer showed more promise. Most encouragingly, respondents agreed that, overall, local knowledge continues to be useful in addressing land degradation, although it is clear that much of this knowledge is at increasing risk of being lost (SC5). On the whole, the variable 'learning and knowledge about land degradation' suggests weakening community resilience (see Figure 2).

In summary, bonding capital in the four communities is at best only moderately well developed, suggesting that some social processes within these communities may be more of a hindrance than an opportunity to address land degradation issues - echoing results by Lopez- 
Gunn (2012) with regard to weak bonding capital in Spanish communities threatened by land degradation. However, at the same time, there are also more strongly developed social traits evident, epitomised through the successful San Mauro Cilento cooperative (see above). More encouraging is that the identity of the communities appears to remain relatively strong, with most respondents identifying closely with 'their' community. This is of particular relevance to a community's ability to respond to land degradation issues, as a relatively coherent community identity means that residents may 'stick together' when faced with adversities related to land degradation (Adger, 2000; Wilson, 2012a). Thus, the fact that some social aspects in the four communities are still moderately well developed suggests both positive residual social memory that could be further harnessed to improve land degradation responses, and an existing (but declining) potential for improvement of social capital. Key examples include finding ways to keep more young people in the community or to improve inter-generational exchange of information and skills.

If bonding capital is only moderately developed, bridging capital is even less well developed in particular with regard to 'horizontal' stakeholder interactions across communities and the Alento region and beyond - again echoing recent findings by LopezGunn (2012) for Spanish communities. This is true with regard to both the relative 'distance' between stakeholders in the four communities and regional policy-makers - such as Cilento and Vallo di Diano National Park officials and institutions and organisations within the park boundaries - as well as to weak trust outside of the community in regional politicians and organisations such as NGOs. Indeed, many stakeholders commented on the lack of trust they felt in politicians and other stakeholders. Relationships with the Cilento and Vallo di Diano National Park authority is particularly strained due to terrace damage by wild boar - a species which is protected by the National Park. The Park has banned boar hunting and administrative procedures for farmers to claim compensation for damage are long and complicated. One respondent argued that "the Park was met with great enthusiasm by locals when it was first established, but now we see that the Park is creating more problems than it is solving" (SC10). Despite of bringing in more income through tourism, the Park is, thus, seen as a source of reduced resilience with regard to options for alleviating land degradation.

Beyond social capital, an important socio-psychological lock-in is associated with social memory and traditions and how these shape community responses to land degradation (see Figure 2). In the four study communities, traditions and social memory revolve largely around olive grove planting and management as an important aspect of long-term soil management processes ${ }^{3}$. Although modernisation of olive oil production is evident in all communities through increased mechanisation and planting of new olive tree varieties, most respondents argued that current production remains much the same as in the past, in particular with regard to the use of olive trees that are often centuries old, traditional pruning techniques, and wide irregular spacing of trees seen as optimal for quality oil production. Many of the olive plantations in the area are remnants of older groves (using varieties dating back to Roman periods) whose produce was destined solely for local markets. The slow growth of the trees, their age and the modes of production employed largely inhibit implementation of modern farming techniques. Respondents argued that the olive quality and yield of these ancient trees is the same as newer high yielding varieties, but the smaller size of traditional trees, their denser shape, and their root systems are better for soil protection than newly established plantations. Lock-ins associated with the social memory of traditional olive cultivation, thus, appear to be positive for raising resilience in all four communities,

\footnotetext{
${ }^{3}$ In San Mauro Cilento this can be traced back through official documents to AD1092 when Italo-Greek monks began cultivating the steep slopes in the area.
} 
evidenced by comments such as "traditional methods are the most sustainable for protecting the soil" (V7).

Nonetheless, there is also evidence of the loss of social memory, as new farmers are less keen to follow local advice (see above), meaning that old trees are often replaced by new varieties that can be planted more densely but are more resource intensive, leading to further land degradation. Several interviewees argued that degradation of terraces is often due to loss of local skills, workers, and loss of social memory as family farm succession is lost. A craftsman from Petrosa, therefore, argued that "olive plantation management was influenced in the past by the rites and traditions of previous generations, but that is no longer the case" (P5). Most respondents, therefore, felt that there was a gradual loss of knowledge and skills associated with sustainable environmental management practices, leading to reduced resilience in the face of terrace collapse, land degradation, and landslides.

Finally, issues of tradition and social memory are also closely intertwined with psychological conservatism, cultural resistance, and inertia that characterise sociopsychological mindsets. An agronomist from Petrosa argued that "the main threat to [resilience] is the mentality of local people who are not open to change or innovation" (P3). The same was true for Stella Cilento, where most respondents suggested that the community was 'very conservative' and that residents wanted to keep things the same, and were "not very open to change" (SC2). One interviewee argued that "sadly there is a strong sense of apathy and resignation in the local community." (SC1), while another argued that "the community was more 'avant-garde' in the past when new initiatives and innovation were greeted with enthusiasm and optimism. Nowadays, things tend to stay the same" (V4). Even in San Mauro Cilento, with its successful and regionally highly acclaimed cooperative (see above), there was a mood of conservatism and apathy, as one local farmer highlighted: "I think the greatest obstacle is changing the provincial mindset of the community. People are so opposed to change that instead of accepting the help of the local administration people prefer to plod on as they always have done" (SM9). Psychological conservatism, cultural resistance and inertia have, thus, led to social passivity, even if it leads to worsening soil erosion and landslides. Directly linked to these issues is the weak ability of the community to adapt to change over time, with issues associated with the establishment of the National Park (see above) as a particular example where community members have found it difficult to adapt to change, exacerbated by an ageing population with, arguably, less adaptive capacity (see also Adger, 2000; Sendzimir et al., 2011). This has severe repercussions for community resilience, with only weak self-reliance of communities in dealing with problems, and a general apathy to get involved in political, social, economic or environmental groups or organizations, highlighting possible future problems associated with implementation of successful responses towards land degradation.

\section{Discussion and conclusions: community resilience, lock-ins and land degradation}

Building on authors such as Ostrom (2008), Moser (2010), Cote and Nightingale (2012) and Wilson (2012a, 2013), this study has analysed the relatively unexplored question of the importance of social, economic and political 'lock-ins' for understanding community resilience and land degradation. The study has highlighted that understanding the resilience of communities can be effectively analysed through the lens of 'lock-ins', and that assessment of path-dependent constraints greatly improves understanding of communities' ability or inability to address land degradation. We were particularly interested in lock-ins that emanate from within the communities (endogenous lock-ins), using four case study communities from the Alento region (Campania, southern Italy) affected by land degradation. 
The discussion highlighted how individual lock-ins have affected the resilience of the four case study communities and how this, in turn, has affected the ability of these communities to combat land degradation. Figure 2 showed that most economic/structural and social/political lock-ins have led to a lowering of community resilience in recent decades, suggesting that all four communities have been on a downward trend of gradual loss of resilience with regard to addressing land degradation issues.

However, as various critical commentators have argued, lock-ins do not occur in isolation but are closely interrelated, and tend to be complex, temporally non-linear and spatially heterogeneous (e.g. Stump, 2010; Davidson, 2010; Wilson, 2012a). Therefore, a change in pathway associated with a specific lock-in can have repercussions for other lock-ins and for the ability of a community to address land degradation. The discussion has particularly highlighted that for negative lock-ins that reduce community resilience, vicious circles of self-reinforcing lock-ins are at play that trigger a chain reaction of further decline (Wilson, 2012a) - best highlighted through interlinkages between outmigration of young people, land abandonment, and loss of skills (see Figure 2 above). A spiral of declining resilience with regard to communities being able to address land degradation issues is, thus, often evident.

However, such downward trajectories are not necessarily irreversible and the analysis has also identified improved adaptive capacity to land degradation issues. For example, all four communities appear to still have the human/social/political resources needed to address degradation issues and develop sustainably, although, echoing both Rigg (2006) and Chaskin (2008), the relative poverty of all four communities acts as a severe impediment to raising resilience, and is further exacerbated by weak access to agricultural and non-agricultural funding. Markets for community-based agricultural products were also only moderately well developed, although the San Mauro Cooperative was highlighted as a key initiative that has raised resilience for both its members and the community, with many positive repercussions for land degradation such as better terrace maintenance, the preservation of traditional sustainable environmental management practices, and a re-valuing of traditional skills and knowledge. This has been counteracted, however, by heavy-handed bureaucratic processes that make it difficult for local stakeholders to establish new pathways for the marketing of local products. These processes have been further severely affected by negative infrastructure lock-ins (mainly poor roads and access) that are lowering the resilience of all four communities, and by the post-2008 economic recession that has particularly led to a decline of already meagre tourism income. Inevitably, these lock-ins are closely intertwined with land abandonment, which has worked in two distinctive ways to raise and lower resilience: on the one hand, it has led to degradation of landesque capital (e.g. terraces) exacerbating land degradation processes but on the other hand, it has also led to re-growth of semi-natural vegetation, helping reduce the risk of soil erosion and landslides. Most importantly, all negative economic lock-ins have led to the outmigration of young people - a lock-in in itself that emerges as a key constraint for raising resilience, and that has meant that few sustainable land management skills are now passed on through the generations.

Figure 2 also showed that these economic and structural lock-ins are closely interconnected with social and political lock-ins. Bonding capital was only moderately well developed, with the San Mauro Cooperative (again) emerging as one of the few positive examples with the potential to substantially improve networks and trust between stakeholders in the area, although corruption, weak pathways for learning and knowledge about land degradation, poor governance/power structures within communities, and resulting low pride in the area, have all conspired to reduce resilience. Bridging capital is even less well developed, characterised by weak stakeholder interactions across the communities, poor relationships with policy-makers and regional officials, and closely interlinked with psychological conservatism, cultural resistance and inertia among community stakeholders - 
key aspects that are further undermining resilience. However, social memory and traditions still appear to play an important role in decisions affecting both land management and land degradation alleviation, with the San Mauro Cooperative yet again playing a pivotal role in bringing together stakeholders to share positive skills and knowledge for addressing land degradation.

Nonetheless, as the critical literature on lock-ins and resilience transitions has highlighted, these are highly dynamic processes that are not 'set in stone'. Indeed, there are many examples where vulnerable communities have managed to 'rediscover' resilience in light of severe land degradation problems (e.g. Walker et al., 2009; Fraser et al., 2011; Wilson, 2012a). Thus, although there is a danger that lock-ins such as outmigration of young people or a gradual loss of sustainable management skills may be permanent, in some cases these processes can be reversed. Further, although the impacts of lock-ins appeared to be relatively uniform across the four communities with few differences in 'resilience quality' between upland and lowland communities, San Mauro Cilento, with its successful cooperative, stands out as one of the few positive recent developments in the area. Less than geography such as steepness of terrain or easier access to tourist markets (in the lowlands for example), a key explanation for successful resilience processes in the Alento appears to lie, therefore, in the ability of stakeholders to come together with a common vision (e.g. via a successful cooperative acting as an example of 'best practice'), harnessing remaining knowledge about how to combat land degradation and being willing to pass on this knowledge to the next generation, while at the same time successfully marketing high quality local products. In line with studies by Adger (2000), Davidson (2010) and Wilson (2012a), this highlights that local leadership, enterprise and vision may be more important for addressing the severe land degradation issues that regions such as the Alento are facing than often crude top-down policies and development agendas shaped by far away policy-makers with little or no attachment to the locality. This is not to say that exogenous policies should not play a role in land degradation alleviation at community level, but, as Fraser et al. (2011) and Lopez-Gunn (2012) emphasised, that endogenous potential and how lock-ins affect that potential may have been underestimated (and under-researched) in previous studies of community resilience and land degradation - a key research arena for future community-level land degradation research.

\section{References}

Adger, W.N. 2000: Social and ecological resilience: are they related? Progress in Human Geography 24 (3): 347-364.

Buikstra, E. et al. 2010: The components of resilience: perceptions of an Australian rural community. Journal of Community Psychology 38 (8): 975-991.

Burton, R.J., Kuczera, C. and Schwarz, G. 2008: Exploring farmers' cultural resistance to voluntary agri-environmental schemes. Sociologia Ruralis 48 (1): 16-37.

Chaskin, R.J. 2008: Resilience, community, and resilient communities: conditioning contexts and collective action. Child Care in Practice 14 (1): 65-74.

Cote M. and A.J. Nightingale 2012: Resilience thinking meets social theory: situating social change in socio-economic systems research. Progress in Human Geography 36 (4): 475-489.

Crane, T.A. 2010: Of models and meanings: cultural resilience in social-ecological systems.

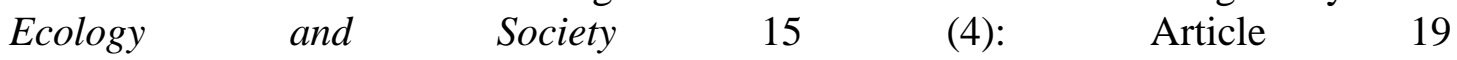
http://www.ecologyandsociety.org/vol15/iss4/art19/. 
Cumming, G.S. et al. 2005: An exploratory framework for the empirical measurement of resilience. Ecosystems 8: 975-987.

Cutter, S.L., Barnes, L., Berry, M., Burton, C., Evans, E., Tate, E. and Webb, J. 2008: A place-based model for understanding community resilience to natural disasters. Global Environmental Change 18: 598-606.

Davidson, D.J. 2010: The applicability of the concept of resilience to social systems: some sources of optimism and nagging doubts. Society and Natural Resources 23: 11351149.

Di Nicola, P., Stanzani, S. and Tronca, L. 2008: Reti di prossimità e capitale sociale in Italia. Milano: Franco Angeli.

Fairhead, J. and I. Scoones 2005: Local knowledge and the social shaping of soil investments: critical perspectives on the assessment of soil degradation in Africa. Land Use Policy 22: 33-41.

Forbes, B.B., Stammler, F., Kumpula, T., Meschtyb, N., Pajunen, A. and Kaarlejärvi, E. 2009: High resilience in the Yamal-Nenets social-ecological system, West Siberian Arctic, Russia. Proceedings of the National Academy of Sciences of the USA 106: 2204122048.

Fraser, E.D., Dougill, A.J., Hubacek, K., Quinn, C.H., Sendzimir, J. and Termansen, M. 2011: Assessing vulnerability to climate change in dryland livelihood systems: conceptual challenges and interdisciplinary solutions. Ecology and Society 16 (3): Article 3 http://www.ecologyandsocietry.org/vol16/iss3/art3/.

LEDDRA 2013: Study of responses to LEDD and of response assemblages in cropland study sites: evaluations and synthesis (Deliverable D213). EU (Brussels): LEDDRA Project.

Lopez-Gunn, E. 2012: Groundwater governance and social capital. Geoforum 43: 1140-1151.

Masten, A.S. and Obradovic, J. 2008: Disaster preparation and recovery: lessons from research on resilience in human development. Ecology and Society 13 (1): Article 9 http://www.ecologyandsociety.org/vol13/iss1/art9.

Moser, S.C. 2010: Now more than ever: the need for more societally relevant research on vulnerability and adaptation to climate change. Applied Geography 30 (4): 464-474.

Oliva, J. 2010: Rural melting-pots, mobilities and fragilities: reflections on the Spanish case. Sociologia Ruralis 50 (3): 277-295.

Ostrom, E. 2008: Frameworks and theories of environmental change. Global Environmental Change 18: 249-252.

Piccaretta, M., Capolongo, D., Boenzi, F. and. Bentivenga, M. 2006: Implications of decadal changes in precipitation and land use policy to soil erosion in Basilicata, Italy. Catena 65: 138-151.

Pomarici, E. and Vecchio, R. 2013: The Italian olive oil industry in the global competitive scenario. Agricultural Economics 59: 361-372.

Resilience Alliance 2007: Assessing resilience in social-ecological systems: a workbook for scientists. www.resalliance.org/3871.php (last accessed 31 July 2013).

Rigg, J. 2006: Land, farming, livelihoods, and poverty: rethinking the links in the rural South. World Development 34 (1): 180-202.

Scheffer, M., Westley, F. and Brock, W.B. 2003: Slow response of societies to new problems: causes and costs. Ecosystems 6: 493-502.

Sendzimir, J., Reji, C.P. and Magnuszewski, P. 2011: Rebuilding resilience in the Sahel: regreening in the Maradi and Zinder regions of Biger. Ecology and Society 16 (3): Article 1 http://www.ecologyandsocietry.org/vol16/iss3/art1/.

Stump, D. 2010: 'Ancient and backward or long-lived and sustainable?' The role of the past in debates concerning rural livelihoods and resource conservation in Eastern Africa. World Development 38 (9): 1251-1262. 
UNCCD 2011: Addressing desertification, land degradation and drought in the context of sustainable development and poverty eradication. New York: UNCCD.

Walker, B.H., Abel, N., Anderies, J.M. and Ryan, P. 2009: Resilience, adaptability, and transformability in the Goulburn-Broken Catchment, Australia. Ecology and Society 14 (1): Article 12 http://www.ecologyandsociety.org/vol14/iss1/art12/

Wilson, G.A. 2012a: Community resilience and environmental transitions. London: Routledge/Earthscan.

Wilson, G.A. 2012b: Community resilience, globalization, and transitional pathways of decision-making. Geoforum 43: 1218-1231.

Wilson, G.A. 2013: Community resilience, policy corridors and the policy challenge. Land Use Policy 31: 298-310.

Xiloyannis, C., Martinez R.A., Kosmas, C., Favia, M. 2008 : Semi-intensive olive orchards on sloping land: requiring good land husbandry for future development. Journal of Environmental Management 89 (2): 110-119. 